\title{
UM ESTUDO HISTÓRICO SOBRE O USO DOS LIVROS DIDÁTICOS DE MATEMÁTICA
}

\author{
Neuza Bertoni Pinto - PUCPR ${ }^{\mathrm{i}}$ \\ neuzard@uol.com.br
}

\begin{abstract}
RESUMO:
O livro didático tem um importante papel na constituição de uma cultura escolar. Longe de ser uma produção neutra, no gesto de ordenar um programa de ensino organiza em seu discurso um conjunto de regras e proposições, considerado o mais adequado para o ensino e aprendizagem de uma disciplina escolar. Enquanto elemento expressivo de uma cultura escolar, não tem um sentido estático e universal. Ao propor um modelo ordenado de interpretação, está sujeito a múltiplas formas de leitura, reformulações, deslocamentos e distorções, dada a recepção inventiva de seus usuários. É no embate entre a proposição do autor e a apropriação feita pelo leitor que se constroem seus múltiplos sentidos. A sala de aula é o celeiro privilegiado dessas complexas relações. Um estudo histórico-cultural do uso do livro didático remete, necessariamente, às práticas escolares que num dado momento e realidade deram-lhe novos sentidos. O objetivo do presente estudo é analisar como o livro didático Matemática-Curso Moderno, de autoria de Osvaldo Sangiorgi foi utilizado nas aulas de Matemática de uma turma de $1^{\mathrm{a}}$. série ginasial, do interior do estado do Paraná, no ano de 1964, momento em que o Movimento da Matemática Moderna chegava às escolas do interior do estado, via livro didático. A apropriação da proposta do autor é analisada a partir de um contexto educacional marcado por significativas mudanças, dentre outras, a ampliação da oferta de cursos ginasiais, a democratização da educação, propiciada pela Lei de Diretrizes e Bases $(\mathrm{LDB} / 61)$ e a proposta de modernização da matemática escolar. O estudo mostra o sentido dado pelo usuário ao novo objeto cultural colocado em circulação, no momento em que a escola secundária, a matemática do curso ginasial e o livro didático passavam por radicais transformações.
\end{abstract}

Palavras-chave: História da Educação Matemática. Livro Didático. Matemática Moderna. Cultura Escolar.

\section{A HISTORIC STUDY ON THE USE OF DIDACTIC BOOKS OF MATHEMATICS}

\begin{abstract}
:
A didactic book greatly influences in the constitution of a school culture. Not as a neutral production, but aiming at conducting its contents, a teaching program organizes in its discourse a great deal of rules and propositions, always considering the most appropriate for the teaching and learning of a school subject. While being a school culture expressive element, the didactic book does not have a static and universal meaning. When the didactic book intends to offer an ordenated model of interpretation, it can have multiple ways of interpreting, restating, dislocating and distorting, depending on the inventive reception of its users. In the battle between the author's proposition and the reader's approach its multiple meanings are constructed. The classroom is the privileged barn of these complex relations. A historic study on the use of a didactic book necessarily refers to school practices, which in a given moment and reality provided new meanings. This work intends to analyze how the didactic book Matemática-Curso Moderno, by Osvaldo Sangiorgi, has been used in Mathematics classes of a first grade of elementary school, in the countryside of Parana state, in 1964, period in which the Movimento da Matemática Moderna was
\end{abstract}


heading in schools of the countryside through didactic books. The use of the author's proposition is analyzed from an educational context known by its significant changes, among others, the enlargement of grade school courses, the democratization of education fostered by Lei de Diretrizes e Bases (LDB/61) and the intent to modernize Mathematics in schools. The study shows the meaning given by the user to this new cultural object avaliable at a time when grade school, grade school Mathematics and the didactic book were going through dramatic changes.

Key-words: History of Mathematics Education. Didactic Book. Modern Mathematics. School Culture.

Segundo Chopin (2004), de uns vinte anos para cá, há um interesse crescente nas pesquisas sobre o uso e recepção do livro didático e dentre outras questões, o autor faz as seguintes indagações acerca do uso desse material: "Que tipo de consumo se faz deles? Os educadores os seguem fielmente, passo a passo, ou tomam certas liberdades em relação à organização que eles propõem? E, nesse caso, quais e por quais razões?” (p.565).

Para Chartier (1999), "as normas e convenções de um livro definem para cada comunidade de leitores, os usos legítimos do livro, as maneiras de ler, os instrumentos e procedimentos de interpretação" (p.13). No caso do livro didático de Matemática, trata-se de um material escolar permeado por uma concepção de educação, de ensino e de aprendizagem, portanto, uma produção que remete o leitor ao lugar de onde fala o autor, portanto, ao contexto educacional que permitiu, num dado espaço/tempo, a circulação de idéias, procedimentos didático-pedagógicos e convenções estabelecidas para a concretização de um currículo escolar.

Face às diferentes possibilidades de leitura que um livro didático oferece, cabe ao historiador reconstruir as formas que diferenciam os "espaços legíveis" e as circunstâncias da "efetuação" da obra, mostrando o distanciamento entre as normas prescritas pelo autor e os procedimentos contemplados pelas práticas concretas e modos de interpretar o texto (Chartier, 1999).

Se o uso de um livro escolar é sempre uma prática que constrói significados para a materialização dos conhecimentos escolares, três questões básicas a serem consideradas na escrita dessa história seriam: Quais as práticas que deram significado ao livro didático num determinado tempo escolar? Quais significados essas práticas construíram? Qual o sentido desses significados?

Na tentativa de melhor compreender os elementos dessa história, o presente estudo faz uma breve análise dos livros de Osvaldo Sangiorgi ${ }^{\mathrm{ii}}$, destinados ao curso ginasial: o primeiro, mais tradicional e com grande circulação, no ensino secundário brasileiro, até início da década de 1960 e o segundo por apresentar de forma pioneira, no Brasil, um programa moderno de Matemática, traçando uma linha divisória entre o clássico e o moderno ensino da matemática escolar ministrado nos cursos ginasiais, configura-se como um veículo relevante de disseminação do Movimento da Matemática Moderna.

Buscar, portanto, os significados do uso desses manuais escolares é o que pretende o presente estudo. Para tanto, toma como fontes de análise, edições históricas ${ }^{\text {iii }}$ dos referidos materiais, além de depoimentos pessoais da autora que no início de sua atuação no ensino secundário, utilizou os referidos livros nas aulas que ministrava às primeiras séries ginasiais. 


\section{O livro didático em meados do século XX}

A disciplina Matemática, ministrada nos cursos ginasiais, ainda na década de 1950, apresentava-se altamente seletiva, contemplando em seu ensino uma exaustiva prática de exercícios, de memorização de definições e demonstração de fórmulas. Voltada para o cultivo da mente, conservava os códigos da educação clássica ofertada, durante o Estado Novo, a uma pequena parcela da população brasileira. Com um conteúdo enciclopédico, caracterizado pelo rigor, formalismo e generalização, o ensino da matemática ginasial distanciava-se do caráter intuitivo e experimental da matemática ministrada na escola primária, fortemente marcada pelos princípios do Movimento da Escola Nova.

Auxiliares indispensáveis no cumprimento do programa oficial do ensino secundário, os livros didáticos da época, cujas edições se repetiam, seguiam as reformas prescritas pelas Portarias 966, de 2/10/51 e 1051, de 14/12/51. O uso do livro didático pelo aluno ginasial restringia-se à consulta das definições, ao estudo das demonstrações e à cópia dos enunciados dos exercícios nos cadernos. A maioria das aulas era expositiva, centrada na ação do professor e na prática de exercícios, cujos procedimentos eram passo a passo explicados pelo mestre. O livro didático era, portanto, um material secundário para o aluno e que perdia de longe para o caderno escolar. Para o professor, o livro era um importante auxiliar para o cumprimento do programa oficial. Situação que começa a modificar-se com as novas aberturas dadas ao ensino secundário a partir da Lei 4024/61.

Como observa Gatti (2004, p.34), referindo-se a esse período, "os livros didáticos assumiram um papel duplo: o de portadores dos conteúdos disciplinares e o de organizadores das aulas". Essa mudança ocorre, de forma mais expressiva, na disciplina Matemática, ministrada no curso ginasial. A chegada do Movimento da Matemática Moderna no Brasil e a significativa reestruturação dos conteúdos programáticos dos cursos ginasiais impactam, sobretudo, a produção dos livros didáticos de Matemática. Os autores mais reconhecidos no mercado editorial renovam suas coleções, alterando não apenas o conteúdo programático, também a forma didática da organização da matéria. Os livros de Matemática Moderna, substituindo as versões anteriores do mesmo autor, incluem novos elementos gráficos e formas didáticas, buscando despertar maior interesse e motivação dos alunos para a matemática escolar.

Tais transformações não ocorrem isoladamente. O cenário educacional brasileiro da época sinalizava para um quadro de grande expansão dos cursos ginasiais, principalmente na região sul do país, que na época incluía o estado de São Paulo. Os Anais dos Congressos Brasileiros do Ensino da Matemática, realizados na década de 1950, registram críticas ao programa excessivo e ao arcaísmo dos métodos vigentes na matemática ginasial. Reavivando velhas discussões, como as encetadas durante o primeiro movimento de modernização da disciplina, liderado por Euclides Roxo, na Reforma Francisco Campos, em 1931, além da revisão dos conteúdos programáticos, os Anais destacam, dentre outras recomendações aos professores do secundário, a adoção de uma pedagogia ativa e o uso do método heurístico.

\section{O uso do livro didático de Matemática}

Para Chartier( 1999), é no encontro de uma "proposição" com uma "recepção" que são construídos os significados de uma determinada obra. Ao considerar que a leitura, "é sempre uma prática encarnada em gestos, em espaços, em hábitos", apesar do sentido dado pelo autor do livro, ao enunciar a interpretação considerada "correta", o usuário/ leitor tem 
uma "liberdade infinita" para reinventar a obra, para buscar, nas suas entrelinhas, novas formas de uso e novos modos de interpretar o texto.

$\mathrm{O}$ relato que ora apresentamos, acerca do uso do livro didático de Matemática remete aos desafios enfrentados pela autora, no início de sua trajetória profissional ( Pinto, 2008). ${ }^{\text {iv }}$ Professora normalista, assumia no início da década de 1960, aulas de Matemática numa turma de $1^{a}$ série ginasial, momento de grande expansão dos cursos ginasiais e das

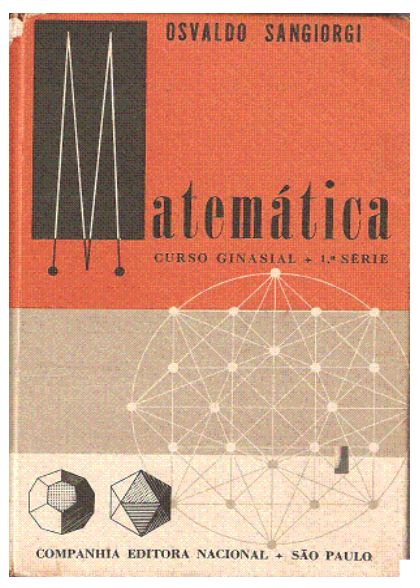
primeiras iniciativas de propagação do Movimento da Matemática Moderna no Brasil. A relação que mantinha com o tradicional livro de Sangiorgi, desde a década de 1950, quando aluna do curso ginasial, davam-me uma certa segurança para utilizá-lo como docente. Como professora iniciante, no ensino secundário, planejava cuidadosamente as aulas, adotando formas intuitivas para organizar as lições do livro Matemática: Curso Ginasial, de autoria de Osvaldo Sangiorgi. A turma da $1^{\text {a }}$. série ginasial era constituída de ex-alunos que já tivera a oportunidade de acompanhar na escola primária local. O fato de dominar o programa e estar sintonizada com os códigos culturais da clientela, dava-me um certo conforto para desenvolver, com relativa segurança, o programa oficial. Como professora "polivalente" no curso primário, considerava também o fato de estar acostumada a arriscar ousadas experiências didáticas, inspirada na literatura educacional que dispunha na épocav

Além da Revista de Ensino e dos livros da coleção de Malba Tahan, consultava o livro "Práticas Escolares", de Antônio D’ Ávila, um dos referenciais didáticos herdado das aulas de Práticas de Ensino do Curso Normal, mas que não oferecia sugestões específicas para a Matemática do curso secundário. Entusiasmada com o livro de Sangiorgi, era desafiada a buscar em outros autores, estratégias didáticas apropriadas para tornar mais dinâmicas as aulas de Matemática. Consultava as obras: "Didática Geral para o Ensino Secundário", de Imídeo Nérici; "Escola Secundária Moderna”, de Lauro de Oliveira Lima e "Sumário de Didática Geral", de Luiz Alves de Mattos. Nessas obras, além de encontrar algumas técnicas para o ensino secundário, deparava-me com uma base teórica acerca da adolescência e de suas características, fundamentos que não havia estudado na Escola Normal. Eram ensinamentos que me auxiliavam na condução da classe, na manutenção da disciplina e no enriquecimento dos planos de ensino. Com eles, ousava criar novas dinâmicas para trabalhar os temas e atividades propostos pelo livro de Sangiorgi. Nada muito específico para a Matemática forneciam esses autores, a não ser alguns conceitos da Psicologia Genética de Piaget, apresentados por Lauro de Oliveira no final do livro.

Foi a partir dessas leituras que experimentei a técnica de "estudo dirigido", proposta por Nérici, enfrentando os desafios do longo tempo necessário à preparação da unidade didática e também das dificuldades encontradas para mimeografar as atividades propostas para os alunos. Lembro-me de ter retomado o "estudo dirigido", ao final da década de 60, quando conheci a obra de Luís Alberto Souza Brasil: "Estudo Dirigido de Matemática" e os "Cadernos do MEC", elaborados por Manoel Jairo Bezerra. Nesses manuais pedagógicos, encontrei mais estímulo para fazer provocações aos alunos, atitude que almejava assumir, de devolver com outras perguntas suas indagações.

O livro de Sangiorgi, destinado à $1^{\mathrm{a}}$. série ginasial, não trazia grandes alterações de uma edição para outra. Continuava com as raríssimas figuras, como no meu tempo de ginásio, apresentando a teoria e destacando em cor vermelha os títulos, os tópicos e sinalização detalhes importantes do tema tratado. Em 1963, na $115^{\text {a }}$ edição, entretanto, o autor informava, no Prefácio, que o livro da $1^{\mathrm{a}}$. série ginasial tornara-se mais atraente, com 
a sugestão do Laboratório de Matemática, atividade em que o aluno poderia, por exemplo, fabricar sua "caixinha de numeração", com a possibilidade de aprender outros sistemas de numeração. Na página 31, dessa edição, Sangiorgi dizia, no decorrer do primeiro capítulo: "A finalidade é propiciar um contacto com as primeiras idéias de grupo e de ordem que, sem dúvida, constituem toda a base da matemática moderna". Além do sistema de base dez, o autor fazia uma breve introdução na programação de outros sistemas de numeração, dando como exemplo, os princípios do sistema quaternário, incentivando cada aluno a fabricar seu material de contagem e realizar experiências no Laboratório de Matemática. Em nota de rodapé, na página 33, o autor informava que esse método estava em vigor na $1^{\text {a }}$. série da Classe Experimental do Colégio de Aplicação da Faculdade de Filosofia, da Universidade de São Paulo, pelo professor Scipione Di Pierro Netto.

Empolgada com a "inovação", procurei colocá-la em prática na sala de aula. Foi fácil confeccionar, com os alunos, as caixinhas sugeridas e providenciar os grãos para as contagens. No lugar das "tradicionais" aulas: explicação no quadro, resolução de exercícios individuais, tarefas para casa, a aula era iniciada com as caixinhas de numeração posicionadas em cima das carteiras. Dava explicações e os alunos faziam individualmente as operações registradas no quadro negro. Em seguida, os alunos eram reunidos em grupos para resolver os exercícios diferenciados que preparara sobre o mesmo tema e distribua a cada grupo em folhas mimeografadas. Era um exaustivo trabalho: não era muito comum, nessa época, trabalhar em grupo nas classes ginasiais. Ali, a disciplina parecia comportar maior rigidez que na escola primária. $\mathrm{O}$ controle da presença dos alunos às aulas era exercido para além da sala de aula. Diferentemente da escola primária, no ginásio, a cada dia as "cadernetas escolares" eram carimbadas na entrada e na saída do recinto escolar e qualquer ocorrência disciplinar era registrada nesse dispositivo escolar, para conhecimento dos pais. Apesar desse controle, considerava a balbúrdia da classe, na hora de formar os grupos, como uma experiência necessária para a consolidação de um ensino ativo, forma didática que havia internalizado nas práticas vivenciadas na Escola Normal.

O programa era rigorosamente cumprido e os exames comprovavam o quanto se havia trabalhado no ano letivo. Os temas, semanalmente "trabalhados" nas aulas e nas tarefas de casa, ficavam também registrados nos cadernos dos alunos. A imagem da matemática era a de um edifício que ia, aos poucos, sendo construído com rigor, milimètricamente assentando-se tijolo por tijolo, sem deixar vácuo que comprometesse sua edificação. Uma condição para o aluno "ir bem na escola" era possuir os livros adotados pela escola. Para a disciplina Matemática, cada aluno deveria ter seu próprio manual que era, na verdade, muito pouco utilizado pelo aluno. O livro, nessa época, servia quase que exclusivamente para o aluno localizar e transcrever os enunciados dos exercícios nos cadernos e depois resolvê-los; quando muito, para um aluno mais interessado, rever modelos e processos de resolução dos exercícios. Os alunos utilizavam mais os cadernos. Não se escrevia nada no livro. Como nos tempos em que cursara o Ginásio, solicitava, na lista de material, dois cadernos: um de rascunho especial para Matemática, geralmente de 200 folhas; outro, menos espesso, para o registro dos "exercícios-tipo", modelos que a cada dia, ao final da aula, indicava para os alunos. Nele, os exercícios eram copiados à tinta, com toda ordem e legibilidade possível, pois, além do objetivo voltado para o desenvolvimento do raciocínio, o ensino de Matemática também buscava desenvolver hábitos de ordem, clareza e concentração, uma velha herança da educação humanística. No caderno de rascunho, os exercícios eram copiados e resolvidos a lápis e podiam ser apagados e corrigidos pelo aluno durante a correção coletiva que ocorria na aula, sempre com um aluno no quadro, demonstrando e explicando o processo de resolução. 
Uma tarefa diária era passar a limpo, em outro caderno, copiando a tinta, os exercícios feitos em cada aula. Esse caderno era levado à escola e semanalmente recolhia, aleatoriamente, alguns deles, para verificar o cumprimento das tarefas.

$\mathrm{Na}$ apresentação dos temas, o livro conferia um espaço especial para as definições, o primeiro item utilizado para apresentar os tópicos. As definições eram exigidas nos exames escritos e orais.

As partes que suscitavam maior interesse dos alunos eram os números relativos, a potenciação, os números complexos, conteúdos totalmente novos em relação aos estudados para o Exame de Admissão. Da lista de problemas, os que mais faziam sucesso nas aulas eram os "modernos", ou sejam, os que falavam de satélites artificiais, viagens espaciais, distância da Terra ao sol, enfim, temas ligados à era espacial, o grande assunto do momento. Adolescentes, os alunos gostavam de advinhação, de coleção, e também das propriedades das operações que demonstravam em grupo para os colegas. As expressões aritméticas mais sofisticadas, reunindo frações, potenciação, necessitavam de um tempo maior para a aprendizagem, assim como as dízimas periódicas e os problemas com frações. A distribuição do tempo para o ensino e aprendizagem era bem dosada no planejamento semanal.

Nas aulas, surpreendia-me o bom desempenho dos alunos com os números decimais. Mais tarde descobri que a maioria das famílias dedicava-se ao trabalho agrícola, utilizavam variados e estranhos instrumentos de medida, como a balança de corrente e de pratos, com seus diferentes pesos, adequados para a pesagem e comercialização da variada produção caseira. Os comerciantes locais tinham formas inusitadas de calcular as medidas dos produtos que vendiam, como pesar punhados de parafusos e pregos, ao invés de contálos. O metro de carpinteiro e o fio-de-prumo eram instrumentos muito utilizados na construção das casas de madeira, modalidade de habitação mais popular da região.

A parte de geometria apresentava-se separada da Aritmética. Apesar de aparecer no último capítulo do livro, os detalhes colocados pelo autor eram minuciosamente trabalhados. As aulas de Desenho Geométrico auxiliavam muito nessa parte, especialmente no uso de instrumentos como régua, compasso, esquadro, transferidor, permitindo um bom trabalho de planificação dos sólidos geométricos em cartolina, momentos que a sala de aula de aula transformava-se em verdadeiro laboratório de aprendizagem. Também experimentava, fora da sala de aula, fazer medição do pátio, com passos e utilizando trenas, metro de madeira etc. No final do ano, fazíamos exposição de matérias confeccionados pelos alunos, como trabalhos bimestrais, tarefa que posteriormente transformou-se em feira de ciências. Nessas exposições, a geometria estava muito presente. Até uma casa de madeira, em miniatura, foi planejada e depois executada por um grupo de alunos, filhos de carpinteiros. As meninas mais dedicadas às artes domésticas, confeccionavam cartazes com problemas inventados a partir das receitas da culinária local, como a popular "cuque", o queijo, a polenta e o macarrão caseiro; até as quantidades de erva-mate do chimarrão eram motivos para o cálculo de frações e medidas. Nos exames orais, eram incluídas questões que deveriam ser demonstradas, de forma prática, comparando e manipulando objetos, uma estratégia adotada para minimizar as "decorebas" das definições.

O livro de Sangiorgi instigava-me a realizar inúmeras atividades extra-curriculares que aos poucos foram se intensificando na escola, com a ajuda da comunidade local. Como haviam poucas turmas de alunos e tendo que assumir um novo desafio de dirigir a escola, disponibilizei as salas de aula para os alunos que quisessem, no contraturno, realizar suas tarefas. Algumas mães colaboravam nessa iniciativa e a escola passou a ser um espaço aberto à comunidade. Nas excursões que fazíamos às Sete Quedas (já desaparecidas), 
distante há 60 quilômetros, os pais acompanhavam e ajudavam na "invenção" de problemas e observações para o relatório individual exigido dos alunos.

Uma outra característica do tradicional livro de Sangiorgi era cada capítulo apresentar, inicialmente, a teoria seguida de uma extensa lista de exercícios sobre o tema tratado com as respectivas respostas. Ao final do capítulo, o autor inseria o tópico: "curiosidades históricas sobre o tema abordado", e, conforme o assunto, como no caso das operações aritméticas, o autor apresentava alguns "modelos de problemas" com explicação detalhada dos seus processos de resolução. Para finalizar o livro, o autor desafiava o aluno com uma exaustiva lista de problemas para serem resolvidos, um convite para o professor recapitular todos os temas trabalhados ao longo do ano letivo. Ao final do ano, a classe era subdividida em grupos e durante duas ou três semanas, eram resolvidos todos os problemas da lista. Apesar de extenso, o programa era exequível e cumprido, rigorosamente. Cumprilo, era um compromisso ético para o professor usufruir as férias "grandes". As aulas terminavam em meados de novembro, depois seguiam-se os exames finais e só em fevereiro, recomeçavam as atividades escolares com os exames de segunda época.

Mesmo sem acesso a congressos e cursos de atualização, o trabalho que iniciara com a primeira série ginasial apresentava-se gratificante e configurava-se como um processo de incessante aprendizagem. Apesar de não trazer orientações didáticas explícitas, o livro de Sangiorgi instigava-me a trabalhar, como na escola primária, com um ensino intuitivo, contextualizado, sem perder o rigor científico requerido pelo ensino secundário. Estimulando um "fazer" que valorizava as relações e explorava as propriedades dos números, o livro trazia um repertório de problemas afinizado ao promissor espírito científico que despontava naquele momento histórico. Assim, a experiência docente, realizada com o livro de Sangiorgi, marcou de forma decisiva o início de minha prática profissional no curso ginasial.

\section{O encontro com a Matemática Moderna}

O primeiro contato com a Matemática Moderna se deu pelo livro "Matemática Curso Moderno", de Osvaldo Sangiorgi, publicado ao final de 1963, pela Editora Nacional e que recebemos pouco antes do início do ano letivo de 1964. A primeira surpresa foi em

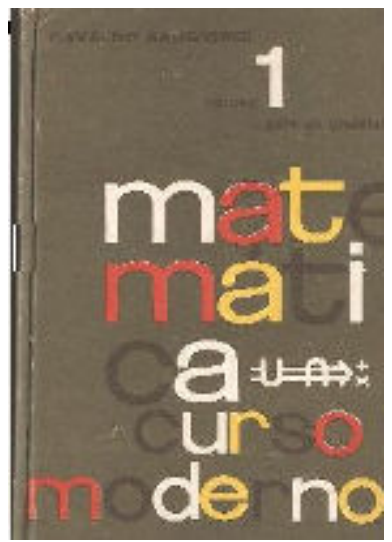
relação às mudanças nos aspectos materiais do livro. $\mathrm{O}$ tamanho do livro era maior, a capa mais colorida e o mais inusitado: o pacote continha um livro em brochura (Caderno de Exercícios), destinado ao aluno e um Guia para uso do professor. À medida que virava as páginas do livro, surpreendia-me com o conteúdo. A primeira impressão é que teria que estudar muito para apreender os novos conceitos. Sem entender o porquê da mudança do programa, nem ao menos atentei ao adjetivo "moderno" que aparecia na capa do livro. Só mais tarde, frente às dúvidas que surgiam, dei-me conta que para um mundo novo que estava despontando o programa anterior, ao qual estava tão familiarizada, poderia não ser suficiente. As palavras do autor na apresentação do livro, confesso que não me causaram grande espanto, os desafios já faziam parte da minha vida profissional e mudar o programa talvez não fosse um bicho-de-setecabeças.

Além da novidade da Teoria de Conjuntos, o novo livro de Sangiorgi estava repleto de símbolos, figuras e de uma variedade de exercícios que se distanciavam das rotineiras e extensas listas que fechavam os capítulos do livro antigo. Pela primeira vez, desde os 
tempos de aluna, tomei conhecimento das novas formas de apresentar os exercícios: de fixação, de aplicação, exploratórios, testes de atenção, estes compreendidos como questões curtas, suscitando uma resolução rápida, sem necessidade de cálculo e uso de lápis e papel. Além dos novos tipos de exercícios, o livro trazia formas "arrojadas" de desenhos, associadas à era espacial, em voga nos jornais e revistas da época. Apesar de manter presentes alguns tipos de exercícios da versão antiga, o novo livro parecia tratá-los de forma mais complicada, a partir de conjuntos, relações, propriedades. Alguns termos causavam-me estranhamento: "numerais de um número", "conjunto vazio", "conjunto fechado". Por que o autor falava tanto em "estrutura", "operação inversa"? Por que ensinar raiz quadrada aos alunos da primeira série ginasial?

Para compreender o primeiro capítulo: Conjuntos e Relações, desenhava várias vezes os símbolos: $\in$ (pertence) e $\notin$ ( não pertence),$\supset$ (contém) e $\subset$ (está contido), tentando assimilar a nova nomenclatura para poder ensiná-la aos alunos. Aprendia que não seria correto dizer que um conjunto é maior ou menor que outro, mas sim que está contido em ou contém outro. Resolvia os exercícios e gostava dos exemplos, como o que mostrava o que era um conjunto unitário, fazendo referência ao Paraná: "Conjunto das capitais do Paraná: \{Curitiba\} e outro relacionado às capitais do Brasil: Assinalar a sentença verdadeira: "Curitiba pertence ao conjunto das capitais de Estados do Brasil". A medida que estudava o novo programa, pensava: "como é fácil essa matemática moderna...os alunos vão gostar muito". Apreciava a forma didática que o autor utilizava para fazer a síntese do assunto abordado, o "Lembrete Amigo", uma forma de lembrar ao professor e ao aluno, que o conhecimento precisa ser sistematizado. A simbologia que se destacava nas lições passava-me a idéia de que a Matemática apresentava-se com uma nova linguagem, com novos códigos de acesso a um mundo que despontava na Era Atômica, como dizia Sangiorgi, na mensagem que endereçava aos estudantes, no prefácio do novo livro.

Como gostava de desenhar, tratei de organizar, para a primeira aula, um cartaz bem caprichado com conjuntos de pessoas, vogais e discos, inspirando-me na página inicial do capítulo 1 do novo livro de Sangiorgi. Tive que suspender o uso do caderno de rascunho, desnecessário ante a novidade do "Caderno de Exercícios" que acompanhava o livro do aluno. Entretanto, comecei a ficar intrigada com o excessivo tempo utilizado pelos alunos para realizarem as tarefas propostas. Estariam dispersos com as figuras? Os enunciados dos exercícios estavam incompreensíveis para eles? Nas primeiras aulas, todos estavam participando ativamente, todos queriam dar exemplos de conjuntos e, de fato o tempo para realizar atividades escritas, na sala de aula, ficava bem reduzido. Retomei o uso do quadro e uma boa porção da aula foi utilizada para explicações, sempre com quatro ou cinco alunos à frente realizando e discutindo as atividades propostas por Sangiorgi. Compreendi que modernizar os conteúdos requeria também modernizar os métodos e com isso, abrir mais espaço para discussão, trabalho em grupo, estratégias que já vinha experimentando em anos anteriores, em que procurava, aos poucos, diminuir o trabalho individual e solitário do aluno e as tradicionais "exercitações".

A terceira parte do livro, referente aos sistemas de numeração e suas diferentes bases, foi a que considerei mais atraente, pois já vínhamos fazendo experiências com as caixinhas de cálculo sugeridas por Sangiorgi, na última edição do livro antigo. A chegada da "modernidade", trazida por Sangiorgi acentuou minha velha preocupação em tornar mais contextualizado o ensino da matemática. 


\section{O apoio didático ao professor}

O suporte imediato para a preparação das aulas de Matemática Moderna era o "Guia para uso dos Professores", complemento endereçado ao professor e que apresentava observações de ordem pedagógica, referências bibliográficas e respostas às questões propostas no livro. Nas palavras dirigidas aos professores, o autor informava sobre as grandes transformações que vinham sofrendo os programas de Matemática em todos os níveis de ensino "dando unidade às diversas partes que, tradicionalmente, eram estudadas em compartimentos estanques, como se existissem diversas 'matemáticas' Destacava que a teoria dos conjuntos era a grande responsável por essa unidade. O Guia fazia referências aos Assuntos Mínimos para um Moderno Programa de Matemática para os Ginásios, propostos pelo Grupo de Estudos do Ensino da Matemática - GEEM e aprovados em 1962, no IV Congresso Brasileiro de Ensino de Matemática, realizado em Belém, no Pará. Foi através desse Guia que tomei conhecimento, pela primeira vez, da existência dos Congressos Brasileiros de Ensino de Matemática e do GEEM; informações que na época não circulavam em todo o Brasil, muito menos na cidadezinha onde estava iniciando minha carreira docente e cujos meios de comunicação eram muito limitados.

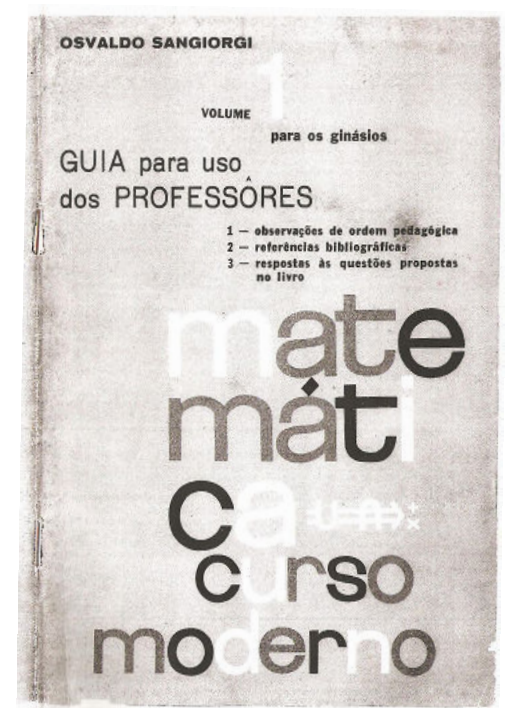

Sem a possibilidade de participar de um curso, daqueles que Sangiorgi mencionava na página 2, do Guia para uso dos Professores, lia e relia, como um mapa da mina, todas as instruções do Guia, com a sensação de que tais orientações haviam sido feitas para professores como eu, que mesmo sem acesso aos cursos, desejava dar um novo sentido à matemática escolar.

Percebia que eram claras as instruções do autor: para cada ítem dos Assuntos Mínimos eram elencadas as ações prioritárias a serem consideradas na execução do novo programa. Dos seis assuntos propostos para a primeira série ginasial, a novidade maior foi mesmo a teoria dos conjuntos, com sua original terminologia. Porém, à medida que avançava nos assuntos que me pareciam familiares deparava-me com novos conceitos que requeriam mais horas de estudo no livro. Assim, fui tomando contacto com os novos conceitos: reunião, intersecção, modalidades de conjunto, numeral, estrutura, propriedades das operações etc, sempre observando as recomendações que Sangiorgi indicava no item: Observações de Ordem Pedagógica, elaboradas para cada capítulo. A preparação das aulas tomava um tempo maior e era sempre iniciada com a leitura do Guia e a resolução dos exercícios indicados no livro didático. Como aprendiz da Matemática Moderna, disciplinadamente, fazia uma espécie de auto-formação, lendo e resolvendo questões do livro, buscando compreender os novos conceitos para depois explicá-los aos alunos. Inúmeras vezes recorria ao dicionário para elucidar melhor o significado de algumas palavras, mas nem o antigo dicionário do Aurélio trazia muitas delas. Atenta a cada sugestão do autor para trabalhar os itens do programa estudava, como aluna aplicada e interessada na matéria, a emblemática Teoria dos Conjuntos contida no livro de Matemática - Curso Moderno.

\section{Considerações Finais}

Para Chartier (1999), todo livro visa uma ordem, seja a ordem de sua decifração, seja a de como deve ser compreendido, ou a ordem desejada pela autoridade que permitiu sua publicação. Entretanto, essa ordem de múltiplas faces, segundo esse historiador da 
leitura, não tem o poder de anular a liberdade dos leitores. Mesmo que limitada por convenções, essa liberdade sabe como dar novos significados ao livro.

O livro didático não tem um "sentido estático, universal, fixo", como sublinhou Chartier (1999) referindo-se aos livros de um modo geral. Seus significados são "plurais" e "móveis" e dependem das expectativas dos diferentes públicos que dele se apropriaram, dos códigos de percepção própria dos seus usuários. Mesmo que o autor, no ato de apropriação, tenha nele fixado um sentido, o usuário também "inventa, desloca e distorce" (p.9), a partir das razões, processos e descontinuidades que historicamente marcaram seu lugar social.

Isso é que parece indicar o relato do uso dos livros de Sangiorgi: as inovações incluídas no livro tradicional estimularam novas formas de ensinar a matemática oficial no ensino secundário. Para além de receituário, o livro colocou novos desafios às expectativas do professor iniciante. Mais que um apoio didático-pedagógico, num momento de transição, o livro Matemática- curso Moderno, foi o porta-voz da "boa nova" que deveria chegar aos responsáveis pelo ensino da matemática escolar, funcionando como "estrelaguia", frente à urgência da difusão de um novo programa e das transformações suscitadas pelo Movimento da Matemática Moderna.

No contexto das mudanças assinaladas, à medida que a memorização vai perdendo terreno nas práticas pedagógicas e que o professor vai deixando de ser o "transmissor" do programa, o livro didático, outrora coadjuvante desse poder docente e de uma prática estritamente alicerçada nas exposições orais e na prescrição de exercícios, ganha um novo sentido.

$\mathrm{Na}$ passagem da matemática tradicional para a matemática moderna, as transformações na apresentação dos exercícios, observadas no livro de Sangiorgi, podem ser compreendidas como vestígios da materialidade escolar na reconfiguração da cultura escolar, de uma primeira ruptura ocorrida na clássica cultura humanística do ensino secundário, em que o aluno valia-se da repetição e memorização para "imprimir" em sua mente a matéria ensinada e com isso cultivar o espírito. Essa ruptura vai se ampliando, e seus sinais podem ser observados na eliminação dos exames orais e de forma mais decisiva na supressão dos exames de admissão ao ginásio e no rompimento do muro que separava o curso primário do curso ginasial decorrente da Lei 5692/71.

Como indica o presente estudo, a mudança do livro didático pode ser compreendida como relevante indício do processo de democratização do ensino secundário desencadeada na década de 1960, pela expansão dos cursos ginasiais, tornando-os mais acessíveis a um maior contingente da população brasileira.

Ao mediar a modernização da matemática escolar, o livro de Matemática Moderna, de autoria de Osvaldo Sangiorgi, cumpriu um papel inusitado, e necessário à atualização do contingente de professores emergentes convocados a ministrar aulas no ensino secundário em expansão. Portanto, seu uso é parte da história da grande reforma que ao propor mudanças estruturais na matemática escolar teve como maior desafio a preparação e atualização dos professores para e o ensino da Matemática Moderna.

A história do uso do livro didático não está, pois, desligada da história das disciplinas escolares, da história das instituições escolares, da história das grandes reformas e movimentos educacionais, sobretudo, da história da trajetória profissional dos professores. Como principal decifrador do sentido dado pelo autor ao livro didático, ao assumir-se como usuário desse importante recurso didático, o professor passa a ser o responsável pela liberdade que lhe é conferida pelo autor para ressignificar a obra. 


\section{Referências Bibliográficas}

CHARTIER, R. A ordem dos livros: leitores, autores e bibliotecas na Europa entre os séculos XIV e XVIII. Brasília: Editora Universidade de Brasília, 1999.

CHARTIER, R. A história cultural: entre práticas e representações. Lisboa: Difel, 1990.

CHERVEL, André. História das disciplinas escolares: reflexões sobre um campo de pesquisa. Revista Teoria \&Educação. Porto Alegre, 1990, n. 2, p. 177-229.

CHOPIN, Alain. História dos livros e das edições didáticas: sobre o estado da arte. Educação e Pesquisa. São Paulo, v.30, n.3, p. 549-566, set./dez. 2004.

GATTI JÚNIOR, Décio. A escrita escolar da história : livro didático e ensino no Brasil (1970-1990). Bauru,SP: Edusc, 2004.

PINTO, N.B. Na sala de aula com Sangiorgi: uma estrela-guia da Matemática Moderna no Brasil. VALENTE, W.R. ( Org.). Osvaldo Sangiorgi: um professor moderno. São Paulo: Annablume; Brasília: CNPq; OSACO: GHEMAT, 2008, p. 119- 144.

SANGIORGI, O. Matemática . Curso Ginasial. 115ª Edição. São Paulo: Companhia Editora Nacional, 1963, $1^{\text {a }}$ série.

SANGIORGI, O. Matemática. Curso Moderno. 1 ${ }^{\text {a }}$. ed. São Paulo: Companhia Editora Nacional, 1963, V.1 para os ginásios.

SANGIORGI, O. Guia para uso dos Professores. São Paulo: Companhia Editora Nacional, 1963, V.1 para os ginásios.

\footnotetext{
${ }^{\text {i }}$ Professora do Programa de Mestrado e Doutorado em Educação da Pontifícia Universidade Católica do Paraná. Pesquisadora do GHEMAT ( Grupo de Pesquisa da História da Educação Matemática).

${ }^{\text {ii }}$ Renomado educador matemático, reconhecido como um dos principais disseminadores do Movimento da Matemática Moderna, no Brasil. Autor da primeira coleção brasileira de livros de Matemática Moderna, destinada aos cursos ginasiais.

iii Para as análises foram utilizadas: a $115^{\mathrm{a}}$ edição do livro: Matemática -Curso Ginasial - $1^{\mathrm{a}}$ série, publicada em 1963; a $1^{\text {a }}$ edição do livro: Matemática-Curso Moderno, Volume 1, para os ginásios, publicada em dezembro de 1963; a 1ª edição do Guia para uso dos Professores, Volume 1, para os ginásios, também publicada em dezembro de 1963. Tanto o volume 1 da Matemática -Curso Moderno como o Guia que o acompanhava foram adotados pelos ginásios a partir de 1964.

iv Esse relato encontra-se publicado, com maiores detalhes, no $5^{\circ}$ capítulo do livro: "Osvaldo Sangiorgi: um professor moderno", organizado por Wagner Rodrigues Valente e publicado pela Editora AnnaBlume, em 2008.

v Revista do Ensino, uma publicação da Secretaria de Educação do Rio Grande do Sul, disponível na biblioteca do Colégio em que lecionava disponibilizava para a preparação das aulas. Também, nesse período, as obras de Malba Tahan contribuíam para o planejamento didático de aulas de Matemática mais atraentes e contextualizadas.
}

Artigo recebido em: 26/5/2009

Aprovado para publicação em: 31/08/09 